\title{
CONTRIBUTION OF HOTELS AND TRAVEL AGENTS TOWARDS DEVELOPING ECO-TOURISM ACTIVITIES IN KANDY DISTRICT.
}

\author{
S N Sepala Dahanayake and K H R Wijayawardane \\ Department of Hospitality Management, Rajarata University of Sri Lanka
}

Recognizing the significance of eco-tourism, Sri Lanka has been quick to jump on the environmental bandwagon and it had declared the year 2000 as "The year of Ecotourism", and the stage is being set for that purpose. . Kandy is a major tourism destination and it was declared a "World Heritage City". This study was to investigate the existing eco-sites and activities centered around the Kandy region, potential eco-sites and their promotional activities, community benefits, programs launched by classified hotels and travel agents. Study also included views from 100 foreigners and 50 domestic travelers on the existing eco-tourism programs in the area. A survey revealed that only five classified hotels were interested on eco-tourism activities. The popular ecosites identified by hotel managers and tour guides were; Knuckles range, Udawattakele sanctuary, Royal Botanical garden at Peradeniya, Mount Hunnasgiriya, Mahaweli river sides and Hantane mountain range. All the hotels and travel agents included in the study promote bird watching, sight seeing, walking and hiking/trekking. Activities like camping, cycling and motor boating are done on guest's request while some hotels and travel agents conduct butterfly watching, dragonfly watching and visiting remote villages. It was found that nearly $75 \%$ of the activities are organized by travel agents. Identified potential sites were Victoria and Randenigala forests, Dunumadalawa reserve, remote villages like Kalapuraya, Rock child estate, Ambuluwawa bio-diversity complex, Digana forest reserve and Kitulgala, Athough they are not fully explored for eco-tourism. Community benefits from the eco-tourism were found to be least or none except few job opportunities provided by few hotels. However, attention of key stakeholders for community benefits is of paramount importance. Analysis of foreign market profile revealed that their purpose of visit is sceneries, cultural and archacological sites, ecovisits and other were $68 \%, 49 \%, 40 \%$, and $18 \%$ respectively. Similarly proportion of the domestic market were $32 \%, 36 \%, 4 \%$ and $28 \%$. Both foreign and local visitors shoired the same trend on the preferred activities; walking $24 \%$, sight seeing $24 \%$, bird watching $19 \%$, cycling $8 \%$, hiking/ trekking $12 \%$, canoeing/ motor boating $7 \%$, camping $5 \%$.

Proceedings of the Ninth Annual Forestry and Environment Symposium 2003 of the Department of Forestry and Environmental Science, University of Sri Jayewardenepura, Sri Lanka 